\title{
Optimization of roller shape for roller-type onion pot-seeding machine
}

\author{
Seok-J oon Hwang, Ju-Seok Nam* \\ (Dept. of Biosystems Engineering, Kangwon National University, 1 Kangwondaehak-gil, Chuncheon, Gangwon-do, \\ 24341, Republic of Korea)
}

\begin{abstract}
In this study, roller shape optimization was performed on a roller-type pot-seeding machine used for sowing onion seeds. The parameters for optimization were derived by analyzing the operating characteristics of the pot-seeding machine. Based on this, the roller shape was determined to minimize weight while satisfying the required strength. When the optimized roller shape was applied, it was possible to reduce the weight of the roller by $17.7 \%$ compared with the conventional one, while satisfying the safety factor of 2.0 or more. The optimum bed soil compaction required for onion sowing was also obtained. Therefore, applying the roller shape derived from this study to an existing roller-type pot-seeding machine may increase the production efficiency of healthy seedling.
\end{abstract}

Keywords: onion, pot-seeding machine, roller-type, shape optimization

DOI: $10.25165 /$ j.ijabe.20201301.3897

Citation: Hwang S-J, Nam J-S. Optimization of roller shape for roller-type onion pot-seeding machine. Int J Agric \& Biol Eng, 2020; 13(1): 111-119.

\section{Introduction}

Onion is a major vegetable, which has the second largest cultivation area worldwide, specifically, $65796840000 \mathrm{~m}^{2}$, and the third largest production capacity, corresponding to $116203767 \mathrm{t}$ in $2014^{[1]}$.

China accounts for $40.4 \%$ of the global onion production and produces seedlings by sowing on pots. The seedlings are transplanted into filed when they are fully grown ${ }^{[2]}$. The onion cultivation area and production amount in China are $22589780000 \mathrm{~m}^{2}$ and $46951457 \mathrm{t}$, respectively, which are the largest in the world with a production per unit area of $2.08 \mathrm{~kg} / \mathrm{m}^{2}$. India, which accounts for $16.7 \%$ of the total onion production, directly sows onion seeds on the open field through manpower ${ }^{[3]}$. India is the second largest global producer after China; its onion cultivation area and production amount are $12035700000 \mathrm{~m}^{2}$ and $19401680 \mathrm{t}$, respectively, and it has a production per unit area of $1.61 \mathrm{~kg} / \mathrm{m}^{2}$. South Korea, which accounts for $1.72 \%$ of the total onion production worldwide, has an onion cultivation area of $402580000 \mathrm{~m}^{2}$ which is the $22 \mathrm{nd}$ in the world, but its production amount is $2052652 \mathrm{t}$, the 6th, with a production per unit area of $5.1 \mathrm{~kg} / \mathrm{m}^{2}$. The reason for the relatively high production per unit area in Korea is attributed to its particular cultivation style. In Korea, a mechanical pot-seeding machine is used to sow onion seeds in pot trays, and the most transplantable high-quality seedlings are mass-produced by integrating and managing the environment of manufacturing, filling, sowing, watering, and fertilizing ${ }^{[4]}$.

Mechanical pot-seeding machines are suitable for efficient onion cultivation because of their low manpower consumption and

Received date: 2018-10-08 Accepted date: 2019-12-05

Biographies: Seok-Joon Hwang, PhD candidate, research interests: agricultural field machinery, agricultural engineering, Email: human51@naver.com.

*Corresponding author: Ju-Seok Nam, PhD, Assistant Professor, research interests: agricultural field machinery, farm power and machinery, reliability assessment. Dept. of Biosystems Engineering, Kangwon National University, 1 Kangwondaehak-gil, Chuncheon, Gangwon-do, 24341, Republic of Korea. Email: njsg1218@kangwon.ac.kr. high working efficiency ${ }^{[5]}$. They are classified into roller and vacuum nozzle types, depending on the operation method. Although sowing accuracy is higher in the vacuum nozzle type, cost and working efficiency are superior in the roller type ${ }^{[6]}$. Considering its higher seeding speed, excellent power transmission efficiency, durability, and low price, the roller-type pot-seeding machine seems more suitable for general use in various countries.

Development of a roller-type pot-seeding machine with improved performance and cost will have a large ripple effect, and that's possible through characteristics analysis and design improvement of the current machine. This study aims at improving the design of the roller-type pot-seeding machine. The operating characteristics of existing roller-type pot-seeding machines were analyzed and the shape of their core component, the roller, was optimized.

\section{Materials and methods}

\subsection{Characteristics analysis of the roller-type pot-seeding} machine

2.1.1 Main components

The exterior appearance of the roller-type pot-seeding machine used in this study is shown in Figure 1. The main components are the pot tray, automatic input device, hopper, roller, seeding device, and power source, and the features and functions of each component are as follows.

(A) Pot tray: The shape of the pot tray used in the roller-type pot-seeding machine is shown in Figure 2. It has 448 seeding holes and has a total length (L) of $619 \mathrm{~mm}$, total width (W) of $315 \mathrm{~mm}$, and hole diameter (D) of $16 \mathrm{~mm}$.

(B) Auto input device: This is the starting part of the pot-seeding machine, and can load up to 20 pot trays and supply them automatically one by one during the sowing operation.

(C) Hopper 1: It primarily supplies bed soil to the pot tray. It is possible to control the feed amount of bed soil and crush the aggregated bed soil through the stirring device.

(D) Roller 1: It primarily compresses the bed soil loaded in the pot tray, and it rotates only when it is engaged with the pot tray 
through face-to-face contact (Figure 3a).

(E) Hopper 2: Secondarily supplies bed soil to the pot tray that has passed through Roller 1.

(F) Roller 2: It serves to secondarily compress the bed soil that was filled in the pot tray; it rotates constantly by receiving power from power source through sprocket and gear (Figure 3b).

(G) Roller 3: It compresses the bed soil for the third time to make room for onion seeds. Roller 3 rotates only when it engages the pot tray, just like Roller 1 (Figure 3c).

(il) Seeding device: The seeding device consists of a seed box, a seed controller, and a seed drum (Figure 4). The onion seeds stored in the seed box are fed one by one into the hole at the drum surface. At this time, the amount of onion seeds to be fed is controlled through the seed controller, and the onion seed that is not seated in the hole is recovered again. When the pot tray is moved to engage with the seed drum, it rotates through face-to-face contact with the pot tray. When the hole of the drum matches the hole of the pot tray, the seeds placed in the hole of the drum do a free fall, so that a single onion seed per pot tray's seeding hole is seeded.

(I) Roller 4: Seeds and bed soil are compressed to secure the seed to the pot tray. Roller 4 constantly rotates by receiving power from power source through sprocket and gear, the same as Roller 2 (Figure 3d).

(J) Hopper 3: It supplies bed soil to the pot for the last time.

(K) Power source: A direct current motor (DC motor) with a reducer is used as a power source to power all the elements of the roller-type pot-seeding machine.

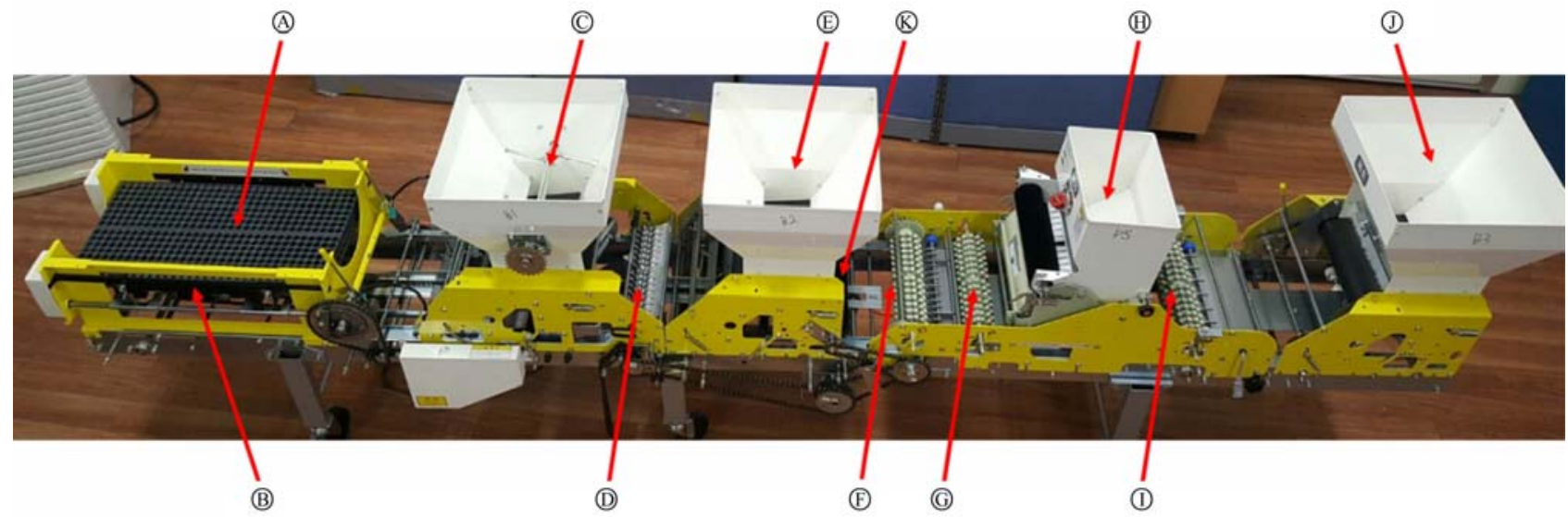

Figure 1 Photograph of roller-type pot-seeding machine
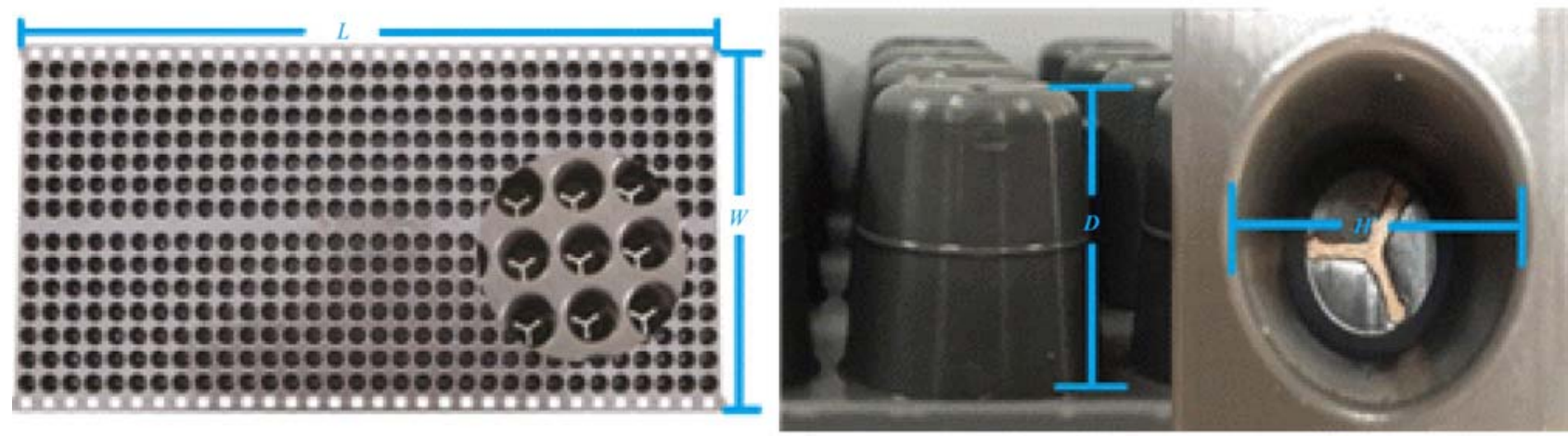

Figure 2 Shape of pot tray



a. Roller 1



c. Roller 3

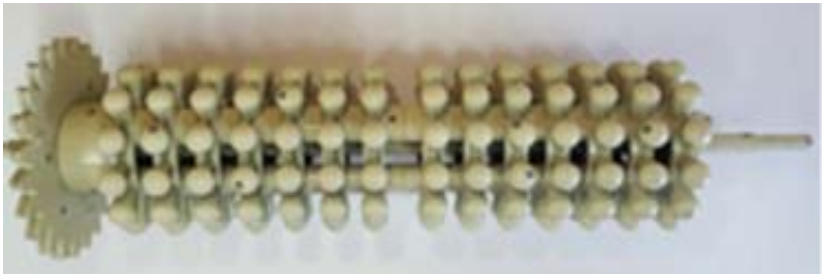

b. Roller 2

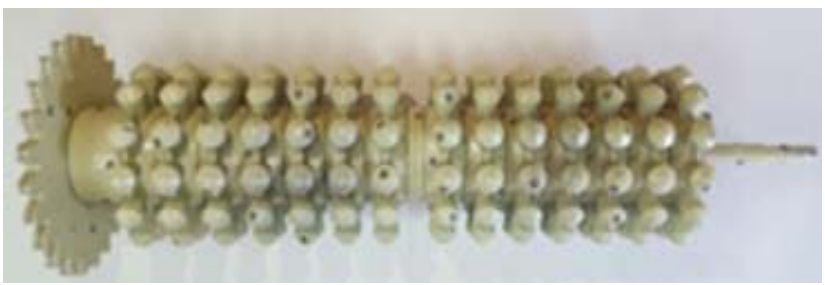

d. Roller 4

Figure 3 Shape of rollers used in the pot-seeding machine 

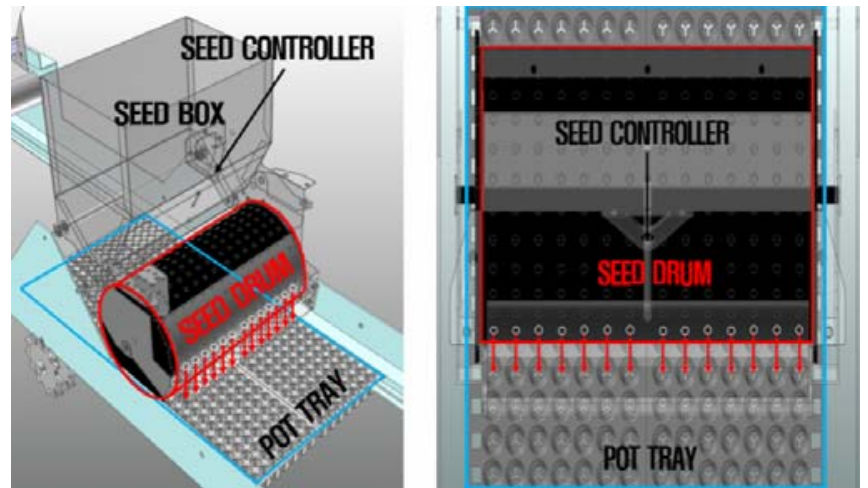

Figure 4 Shape of seeding device

\subsubsection{Power path}

The overall power path of the roller-type pot-seeding machine is shown in Figure 5. The DC motor has a rotational speed of
$1770 \mathrm{r} / \mathrm{min}$ and gear ratio of reducer is $100: 1$, therefore, the rotational speed of the power source's output shaft is $17.7 \mathrm{r} / \mathrm{min}$ The output of the power source is transferred to the pot tray, Rollers 2 and 4, and the chain-sprockets and gears are used as the power transmission elements. There are 5 sprockets and 4 gears in the entire pot-seeding machine, and Table 1 lists the number of teeth for each sprocket and gear.

When the pot tray is supplied through the auto input device, the chain connected to sprocket 1 is fixed to the junction at the bottom of the pot tray, and the pot tray moves at the same linear velocity as the chain. The pot tray moving at a specific linear velocity stops after passing through Rollers 1, 2 and 3, the seeding device, and Roller 4. At this time, the seed drum of the seeding device, Rollers 1 and 3 receive power through the pot tray, and they rotate only at the moment of engagement with the pot tray.

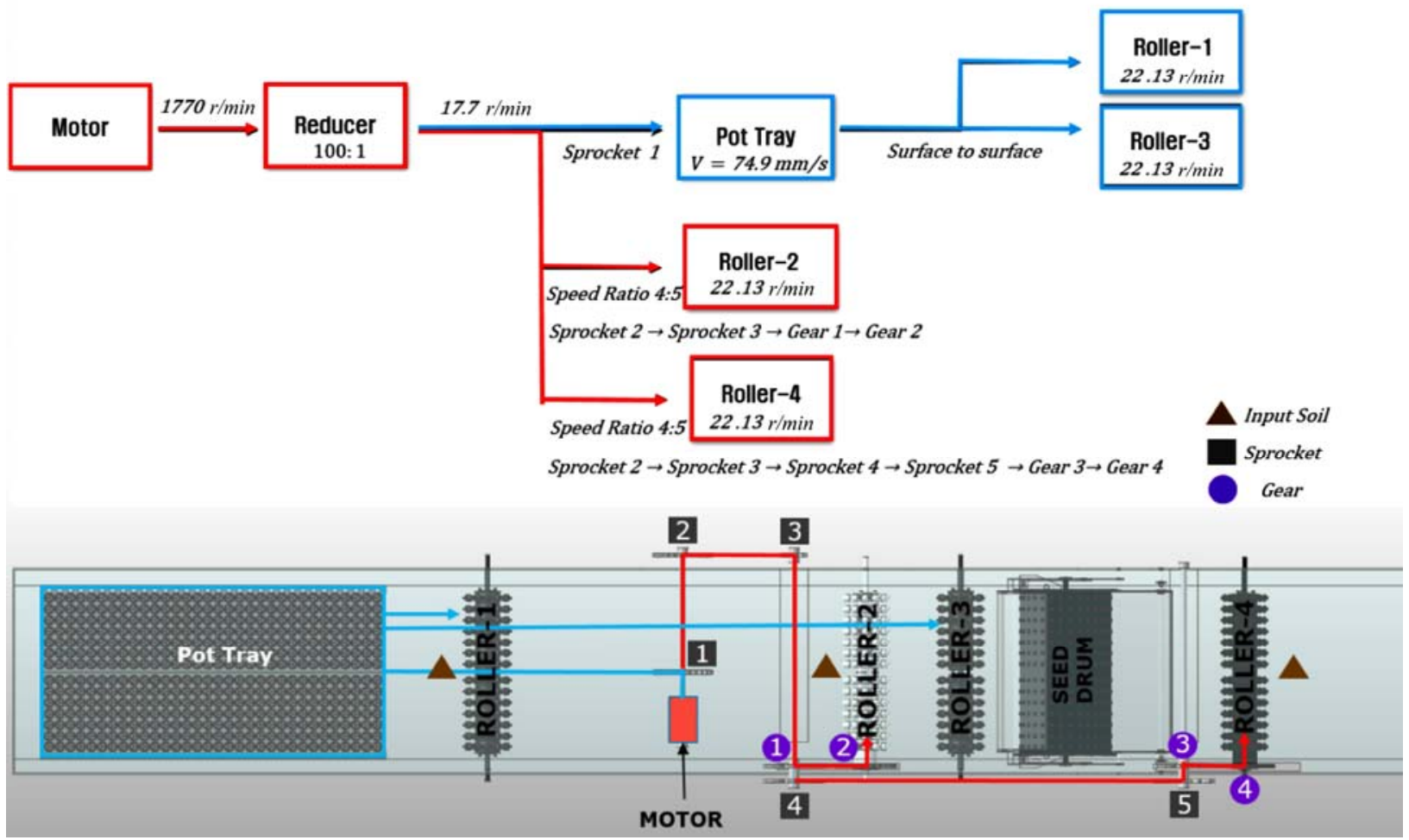

Figure 5 Power path of the pot-seeding machine

Table 1 Number of teeth in sprockets and gears

\begin{tabular}{ccc}
\hline & Number & Number of teeth \\
\hline \multirow{3}{*}{ Sprocket } & 1 & 20 \\
& 2 & 25 \\
& 3 & 10 \\
& 4 & 12 \\
Gear & 5 & 12 \\
\hline & 1 & 12 \\
& 2 & 24 \\
& 3 & 12 \\
4 & 24 \\
\hline
\end{tabular}

Because the pot tray moves at the same linear velocity by engaging with the chain, the linear speed of the pot tray can be determined by Equation (1) ${ }^{[7]}$. The chain pitch is $12.8 \mathrm{~mm}$, and thus, the linear velocity of the pot tray derived from the equation is $7.49 \times 10^{-2} \mathrm{~m} / \mathrm{s}$.

$$
V_{p o t}=\frac{P \times Z^{\prime} \times n}{60000}
$$

where, $V_{\text {pot }}$ is the linear velocity of pot tray, $\mathrm{m} / \mathrm{s} ; P$ is pitch of chain, $\mathrm{mm} ; Z^{\prime}$ is the number of teeth in sprocket; $n$ is the rotational speed of sprocket, $\mathrm{r} / \mathrm{min}$.

Rollers 1 and 3 and the seed drum rotate by face-to-face contact with the pot tray, which is moving at $7.49 \times 10^{-2} \mathrm{~m} / \mathrm{s}$, and their pitch radii are $3.23 \times 10^{-2} \mathrm{~m}, 3.23 \times 10^{-2} \mathrm{~m}$, and $8.85 \times 10^{-2} \mathrm{~m}$, respectively. To compress the bed soil and feed seeds sync with the moving speed of the pot tray, the pitch line velocity of the roller and of the seed drum should be the same as the linear velocity of the pot tray. Therefore, the rotational speed of Rollers 1 and 3 and seed drum can be determined by Equation $(2)^{[8]}$. The calculated rotational speeds of Rollers 1 and 3 , and seed drum are $22.13 \mathrm{r} / \mathrm{min}, 22.13 \mathrm{r} / \mathrm{min}$, and $8.09 \mathrm{r} / \mathrm{min}$, respectively.

$$
N_{r s(1,3)}=\frac{30 \times V_{p o t}}{\pi \times r_{r s(1,3)}}
$$

where, $N_{r s(1,3)}$ is the rotational speed of Rollers 1 and 3 (or seed drum), $\mathrm{r} / \mathrm{min} ; r_{r s(1,3)}$ is the pitch circle radius of Rollers 1 and 3 (or seed drum), $\mathrm{m}$.

Roller 2 is powered by sprockets 2 and 3, and gears 1 and 2, 
and it always rotates. The rotational speed of Roller 2 can be determined from Equation (3) ${ }^{[9]}$, and the calculated speed is 22.13 $\mathrm{r} / \mathrm{min}$.

$$
N_{r 2}=\frac{Z_{g 1}}{Z_{g 2}} \times \frac{Z_{s 3}}{Z_{s 2}} \times N_{\text {input }}
$$

where, $N_{r 2}$ is the rotational speed of Roller $2, \mathrm{r} / \mathrm{min} ; Z_{g 1}$ is the number of teeth in gear $1 ; Z_{g 2}$ is the number of teeth in gear 2; $Z_{s 2} \# \mathrm{~s}$ the number of teeth in sprocket $2 ; Z_{s 3}$ \#is the number of teeth in sprocket 3; $N_{\text {input }} \sharp \mathrm{s}$ the input speed from the power source, $\mathrm{r} / \mathrm{min}$.

Roller 4 receives power through sprockets $2,3,4$, and 5, and gears 3 and 4, and it constantly rotates. The rotational speed of Roller 4 can be determined from Equation (4), and the calculated speed is $22.13 \mathrm{r} / \mathrm{min}$.

$$
N_{r 4}=\frac{Z_{g 3}}{Z_{g 4}} \times \frac{Z_{s 3}}{Z_{s 2}} \times \frac{Z_{s 5}}{Z_{s 4}} \times N_{\text {input }}
$$

where, $N_{r 4}$ is the rotational speed of Roller $4, \mathrm{r} / \mathrm{min} ; Z_{g 3}$ is number of teeth in gear $3 ; Z_{g 4}$ is the number of teeth in gear $4 ; Z_{s 2}$ is the number of teeth in sprocket $2 ; Z_{s 3}$ is the number of teeth in sprocket $3 ; Z_{s 4}$ is the number of teeth in sprocket $4 ; Z_{s 5}$ is the number of teeth in sprocket 5 .

From the power path analysis, the rotational speeds of Rollers 1 and 3, which receive power through the pot tray, and Rollers 2 and 4 , which receive power through the sprockets and gears, are equivalent. To verify this, the pot tray's linear velocity and roller's rotational speed were measured using a tachometer capable of measuring the rotational and linear speeds (Figure 6). The specifications of the tachometer are listed in Table 2. As a result, the speed derived from the above equations and the speed derived from the measurement were the same. Therefore, it can be concluded that the analyzed power path is correct.


Figure 6 Speed measurement by using a tachometer

Table 2 Specifications of the tachometer

\begin{tabular}{ccc}
\hline \multicolumn{2}{c}{ Items } & Specifications \\
\hline \multicolumn{2}{c}{ Model } & TESTO 470, Tachometer kit \\
Manufacturer, Country & TESTO, Germany \\
\hline \multirow{2}{*}{ Measuring range } & Optical & 1 to $99999 \mathrm{r} / \mathrm{min}$ \\
& Mechanical & 0.1 to $99999 \mathrm{r} / \mathrm{min}$ \\
\hline \multirow{2}{*}{ Accuracy } & Optical & $\pm 0.02 \%$ \\
& Mechanical & $\pm 0.2 \%$ \\
\hline \multicolumn{2}{c}{ Resolution } & $1.01 \mathrm{r} / \mathrm{min}$ \\
\hline
\end{tabular}

\subsection{D modeling of roller-type pot-seeding machine}

3D modeling of the roller-type pot-seeding machine was performed. The pot tray and rollers, which require precise dimensioning, were scanned using a high precision 3D scanner, and actual dimensions derived by measurement were used for other components and the supporting frames. The shape and specifications of the 3D scanner are presented in Figure 7 and Table 3, respectively, and the modeling shapes of the main components and the entire pot-seeding machine are shown in Figure 8 .

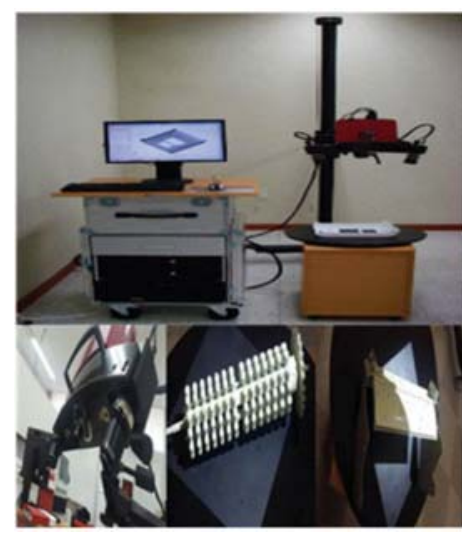

Figure 7 3D scanning of pot tray and rollers

Table 3 Specifications of 3D scanner

\begin{tabular}{lc}
\hline \multicolumn{1}{c}{ Items } & Specifications \\
\hline Model & ATOS-3 3D Scanner \\
Manufacturer, Country & GOM, Germany \\
Resolution & $2048 \times 2048$ pixels \\
Measurement data per iteration & 4000000 points \\
Measurement duration per iteration & $2 \mathrm{~s}$ \\
Measurement area, max $/$ min & $1000 \times 1000 \times 1000 \mathrm{~mm}^{2} / 65 \times 65 \times 45 \mathrm{~mm}^{2}$ \\
Measurement interval, max $/$ min & $1.0 \mathrm{~mm} / 0.07 \mathrm{~mm}$ \\
Precision, max $/$ min & $20 \mu \mathrm{m} / 1 \mu \mathrm{m}$ \\
\hline
\end{tabular}

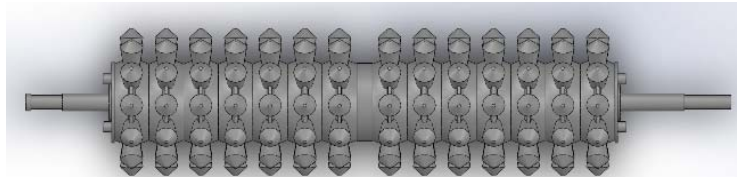

a. Roller 1



b. Roller 2

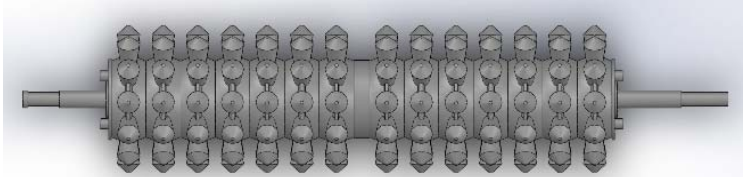

c. Roller 3

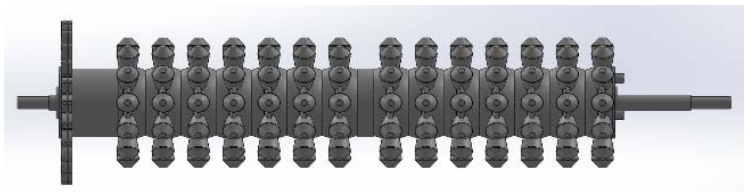

d. Roller 4 

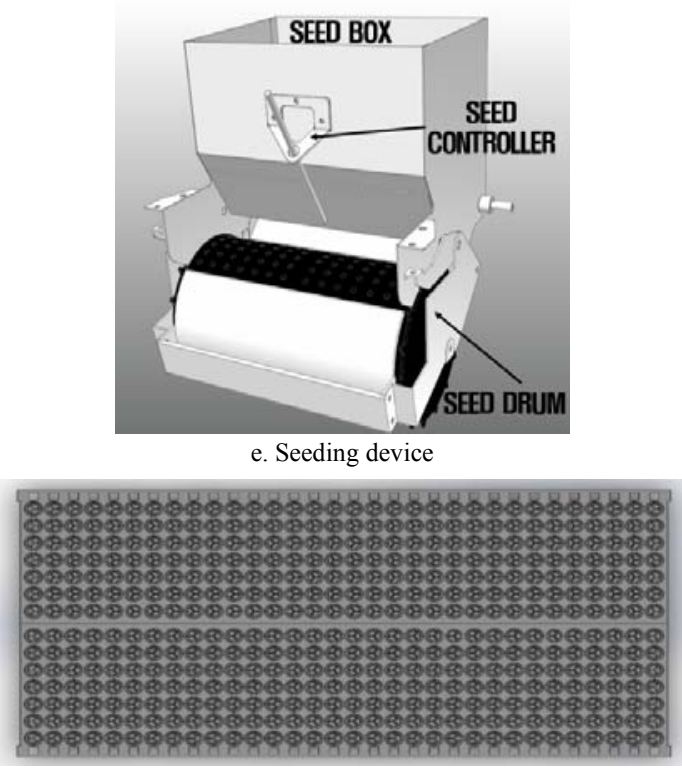

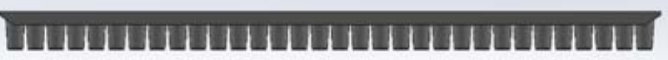

f. Pot tray

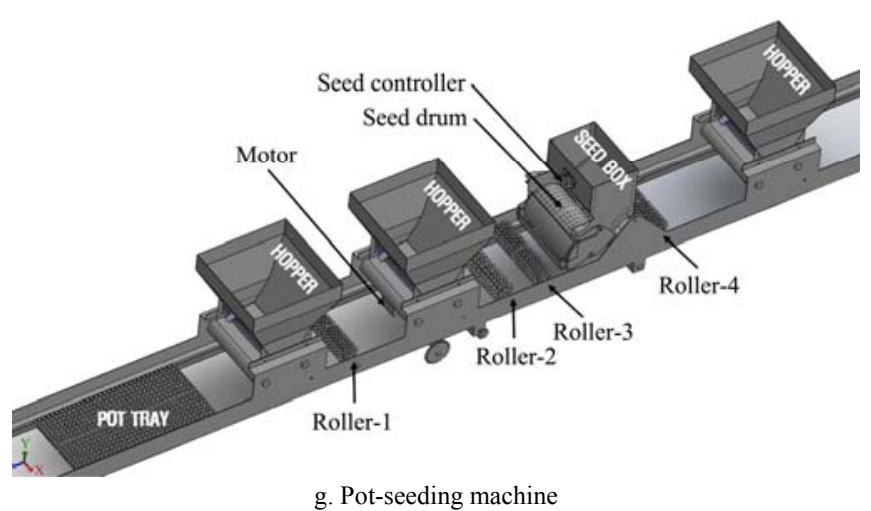

Figure 8 3D modeling of the pot-seeding machine

\subsection{Dynamic analysis}

A dynamic simulation for the pot-seeding machine was performed by using a commercial program (Recurdyn V8R5, Functionbay, Korea) and 3D modeling of the pot-seeding machine.

\subsubsection{Analysis conditions}

The conditions for the dynamics analysis are as follows: the rollers are made of steel, and the physical properties applied to the dynamics analysis are listed in Table $4^{[10]}$. The pot tray is made of $80 \%$ polypropylene (PP), 17\% ethylene propylene rubber (EPR), and $3 \%$ colorant and stabilizer ${ }^{[11]}$. The properties applied to the pot tray were those of PP, which accounts for the largest share of its materials (Table 5) ${ }^{[12]}$. The properties of the bed soil were determined from literature reviews (Table 6) ${ }^{[13]}$. The influence of self-weight was considered, and the values obtained from power path analysis were used for the speed of pot tray, power source's output shaft, Rollers 2 and 4 . The seed drum, Rollers 1 and 3 are rotated through face-to-face contact with the pot tray to reflect the actual operating conditions.

\section{Table 4 Physical properties of rollers}

\begin{tabular}{lc}
\multicolumn{1}{c}{ Items } & Specifications \\
\hline Material & Steel \\
Density $/ \mathrm{kg} \cdot \mathrm{m}^{-3}$ & $7.85 \times 10^{3}$ \\
Poisson's ratio & 0.29 \\
Young's modulus/GPa & 207 \\
Yield strength/MPa & 346.5 \\
\hline
\end{tabular}

Table 5 Physical properties of pot tray

\begin{tabular}{|c|c|}
\hline Items & Specifications \\
\hline Material & Polypropylene \\
\hline Density $/ \mathrm{kg} \cdot \mathrm{m}^{-3}$ & $0.95 \times 10^{3}$ \\
\hline Poisson's ratio & 0.46 \\
\hline Young's modulus/GPa & 0.7 \\
\hline \multicolumn{2}{|c|}{ Table 6 Physical properties of bed soil (cocopeat) } \\
\hline Items & Specifications \\
\hline Material & Cocopeat \\
\hline Bulk density $/ \mathrm{kg} \cdot \mathrm{m}^{-3}$ & $1.5 \times 10^{3}$ \\
\hline Poisson's ratio & 0.25 \\
\hline Coefficient of restitution & 0.35 \\
\hline Coefficient of static friction & 0.44 \\
\hline
\end{tabular}

2.3.2 Simulation Validation

The degree of bed soil compression by Roller 3 was examined from the simulation and experiment to verify the validity of the dynamic simulation applied in this study.

In the experiment, the pot-seeding machine was operated and the degree of bed soil compression was measured by selecting three arbitrary seeding holes in the pot tray passed through Roller 3 . The bed soil was hardened by applying a strong adhesive, and it was cut in its center plane. A white spray was applied to the compression surface of the bed soil to enable visual confirmation of the degree of compression. In the dynamic simulation, the 3D modeling above was applied to the dynamic analysis program, and the degree of bed soil compression in the pot tray through Roller 3 was confirmed.

As a result, in the dynamic simulation, the degree of bed soil compression obtained by Roller 3 was $10 \mathrm{~mm}$ (Figure 9), and the degree of bed soil compression achieved by the actual roller was also $10 \mathrm{~mm}$ (Figure 10). Therefore, the dynamic simulation applied in this study was shown as valid.

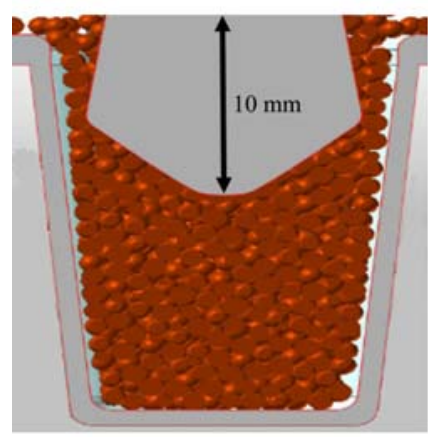

Figure 9 Compression depth of bed soil derived from the dynamic analysis
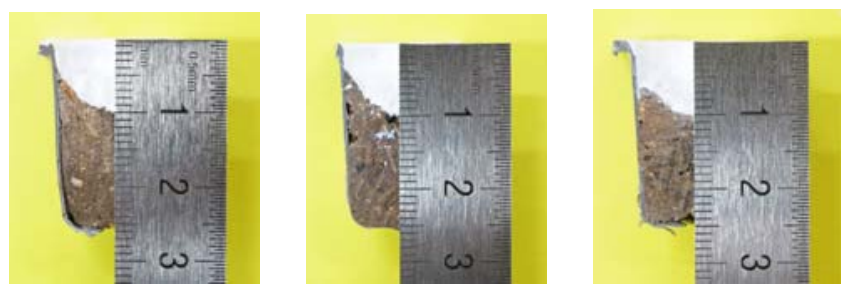

Figure 10 Compression depth of bed soil derived from the experiment (in three randomly selected spots)

\section{Results and discussion}

\subsection{Method for design improvement}

The higher density of the bed soil filled in the pot tray is favorable for onion growth, because of the little root swelling in the 
onion seedlings during the transplantation process. Therefore, the role of the rollers to compress bed soil is important in a roller-type pot-seeding machine. Moreover, when the amount of covering bed soil determined by the seeding depth is larger than the appropriate one, the moisture content of the covering bed soil will be excessive, thus deteriorating onion seedling growth. On the other hand, a less than appropriate amount of covering bed soil can adversely affect growth, because seeds would have insufficient moisture, which is required for germination; therefore, adequate seeding depth is required ${ }^{[14]}$. Roller 3 (Figure 11) is a key factor in determining healthy onion seedling production, because it determines the seeding depth through the compression of bed soil just before the seeding process. Therefore, in this study, shape optimization of Roller 3 was selected as a design improvement goal.

The degree of bed soil compression by Roller 3 protrusions is $10 \mathrm{~mm}$ as shown in Figures 9 and 10. The recommended seeding depth for the seedling production is about $5 \mathrm{~mm}^{[15]}$. Considering that the average radius of the onion seeds used for the pot-seeding machine is $2 \mathrm{~mm}$, the optimal bed soil compression by the roller protrusions would be approximately $7 \mathrm{~mm}$. Therefore, the design improvement task includes reducing the height of the roller top. The optimum value for the height of the roller bracket and the diameter of the roller bottom are also included in the design improvement task because they are related to the roller weight.

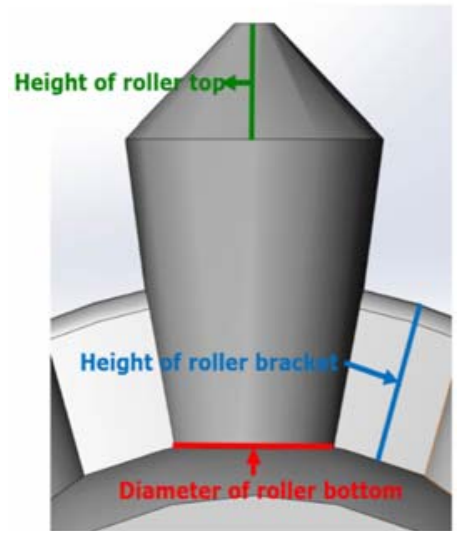

Figure 11 Shape of protrusion of Roller 3

\subsection{Stress analysis for Roller 3}

In Roller 3, twelve protrusions are arranged in the circumferential direction. The upper part of the protrusion is conical and the lower is cylindrical (Figure 12). A bracket is connected between protrusions to support the protrusions.

Dynamic simulations were used to obtain the magnitude of equivalent stress generated on Roller 3. The average size of the mesh for stress analysis was $2.5 \mathrm{~mm}$, and the mesh shape was set as a tetrahedron. As a result, the maximum equivalent stress generated on Roller 3 was $55.1 \mathrm{MPa}$ on the upper end of the bracket (Figure 13). The Roller 3 is made of was steel, with a tensile yield strength of $346.5 \mathrm{MPa}$, and thus, the safety factor was 6.29 .
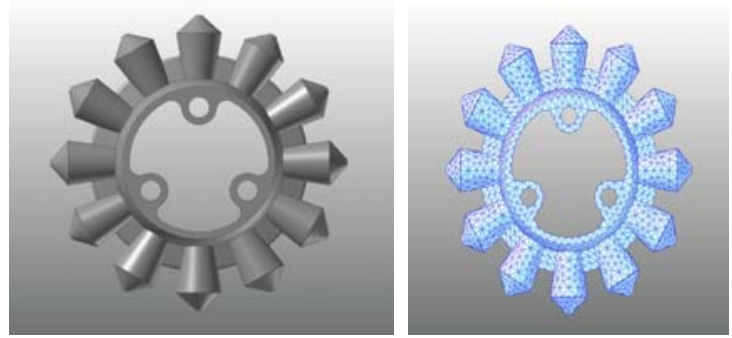

Figure 12 Shape of Roller 3 and mesh for the stress analysis

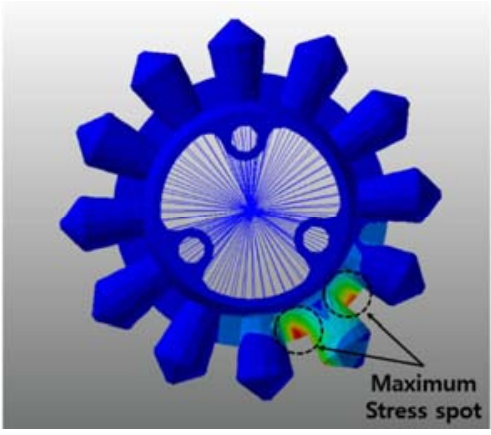

Figure 13 Equivalent stress contour of Roller 3

\subsection{Roller shape optimization}

\subsubsection{Shape optimization conditions}

In Roller 3, the height of the roller top is $5 \mathrm{~mm}$, the height of the roller bracket is $7 \mathrm{~mm}$, and the diameter of the roller bottom is $9 \mathrm{~mm}$.

The height of the roller top directly affects the depth of sowing. To reduce the bed soil compression of the pot tray from $10 \mathrm{~mm}$ to the optimum level of $7 \mathrm{~mm}$, the height of the roller top should be reduced by $3 \mathrm{~mm}$. Therefore, the height of the roller top was reduced from $5 \mathrm{~mm}$ to $2 \mathrm{~mm}$ while maintaining the present form.

The bracket and the bottom of the roller protrusion are the main support for the load acting on the roller. As a result of the stress analysis, the safety factor of Roller 3 is 6.29 , which is considerably high. Therefore, design improvement was performed to adjust the size of the bracket height $(\mathrm{HOB})$ and the diameter of the roller bottom (DRB) to minimize roller weight (Figure 14). The safety factor was selected as the constraint, and the size of the bracket height and diameter of the roller bottom was optimized so that the weight of the roller was minimized, under the condition that the safety factor should be 2.0 or higher. The adjustment range for the height of the bracket and diameter of the roller bottom was determined through a preliminary analysis (Table 7).



Note: a. Height of bracket (HOB). b. Diameter of roller bottom (DRB).

Figure 14 Optimization parameters for Roller 3

Table 7 Ranges of design parameters for optimization

\begin{tabular}{ccc}
\hline Range & $\mathrm{HOB} / \mathrm{mm}$ & $\mathrm{DRB} / \mathrm{mm}$ \\
\hline Lower & 0.6 & 2.5 \\
Upper & 1.8 & 7.5 \\
\hline
\end{tabular}

3.3.2 Shape optimization results

In this study, the optimization problem was solved by using a commercial design program (Easy Design V3R7, Optimal Design Incorporated, Korea). This design program is a commercial optimization tool that uses a sequential approximate optimization algorithm based on a progressive meta-model ${ }^{[16]}$.

Table 8 presents the analysis conditions to find the optimal solution. The basic analysis conditions, No.1 to No.5, reflect the set deviation range, while No.6 to No.12 are sequential analysis 
conditions in the process of finding the optimal solution. The stress distribution in the roller under each analysis condition is shown in Figure 15. It can be seen that the stress distribution generated in the roller changes depending on the size of the design parameters. The maximum stress occurred at the bottom of the roller protrusion or at the top of the bracket.

The optimal solution was achieved at No.12, in which the diameter of the roller bottom decreased from $9 \mathrm{~mm}$ to $6 \mathrm{~mm}$, and the height of the bracket decreased from $7 \mathrm{~mm}$ to $1.5 \mathrm{~mm}$. In this case, the safety factor is 2.1. Applying this shape reduces the roller weight from $1.6 \mathrm{~kg}$ to $1.31 \mathrm{~kg}$, resulting in a weight reduction of $17.7 \%$. Therefore, through the design optimization, it was possible to reduce the roller weight by more than $10 \%$, while the safety factor of 2.0 or more was satisfied.

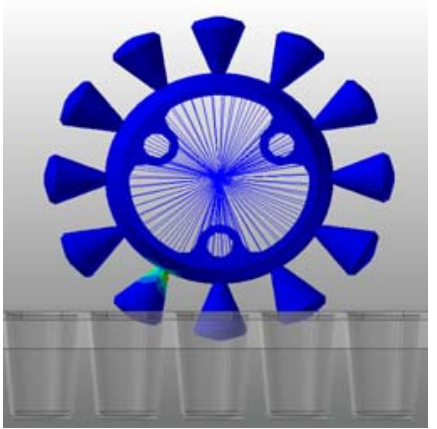

a. No.1

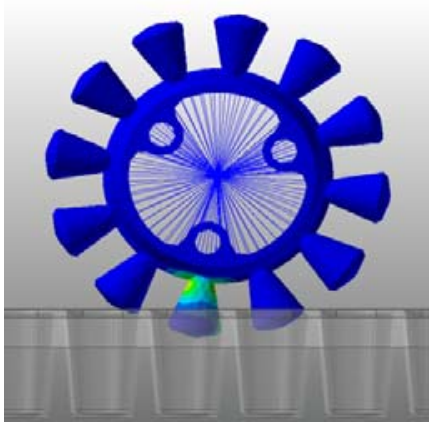

e. No.5

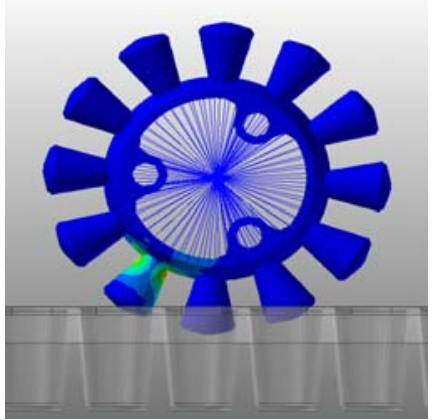

i. No.9

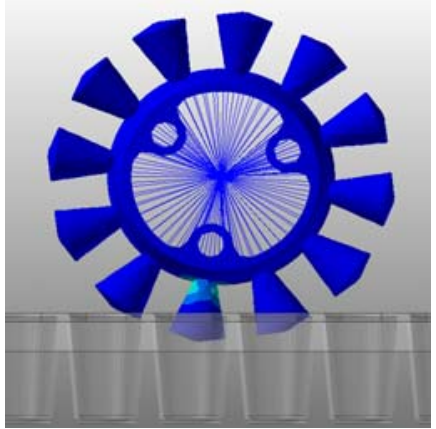

b. No.2

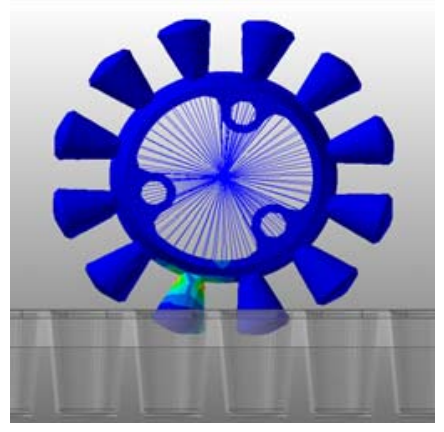

f. No.6

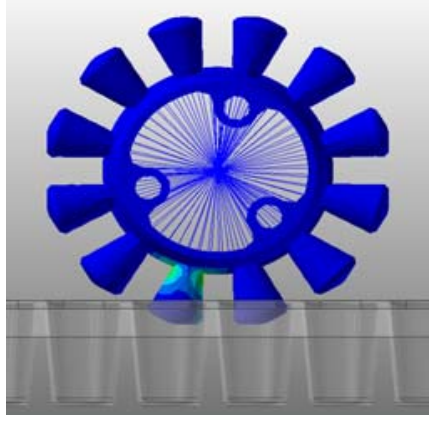

j. No.10

Table 8 Optimized solution for each condition

\begin{tabular}{ccccc}
\hline Number & HOB $/ \mathrm{mm}$ & $\mathrm{DRB} / \mathrm{mm}$ & Mass $/ \mathrm{kg}$ & Safety factor \\
\hline 1 & 1.2 & 2.5 & 1.18189 & 0.30 \\
2 & 1.2 & 5 & 1.27553 & 1.44 \\
3 & 1.2 & 7.5 & 1.37891 & 2.66 \\
4 & 0.6 & 5 & 1.2674 & 0.66 \\
5 & 1.8 & 5 & 1.27488 & 1.66 \\
6 & 1.3 & 5.2 & 1.27488 & 1.71 \\
7 & 1.2 & 5.4 & 1.28565 & 1.69 \\
8 & 1.8 & 5.4 & 1.32334 & 2.68 \\
9 & 1.2 & 6.6 & 1.33573 & 1.98 \\
10 & 1.5 & 6.4 & 1.32819 & 2.45 \\
11 & 1.4 & 6 & 1.31139 & 1.54 \\
12 & 1.5 & 6 & 1.31123 & 2.08 \\
\hline
\end{tabular}

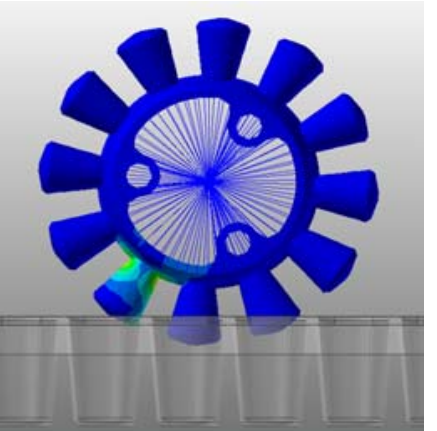

c. No.3

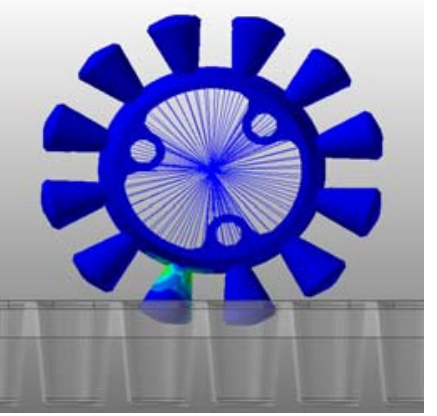

g. No.7

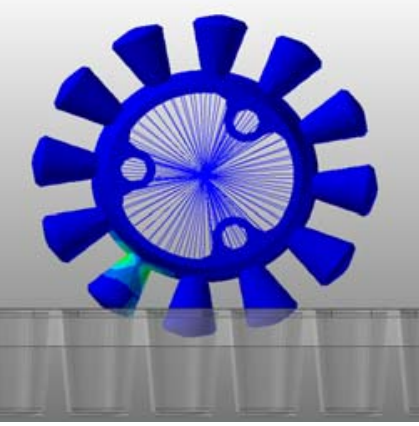

k. No.11

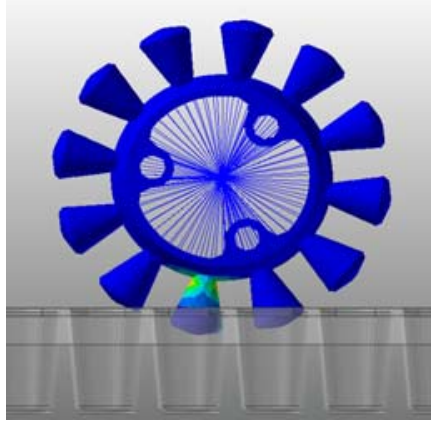

d. No.4

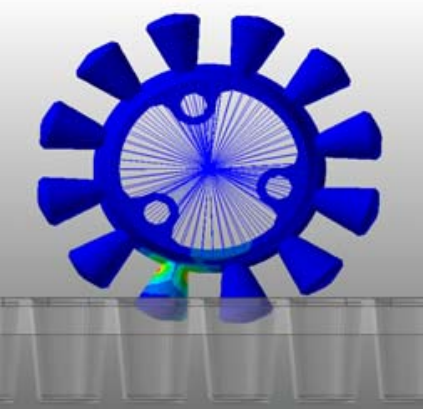

h. No.8



1. No.12

Figure 15 Equivalent stresses occurring at each analysis condition

\subsection{Analysis of bed soil compaction}

A dynamic simulation was carried out to investigate the bed soil compaction from the rollers applying the above derived optimization parameters. Figure 16 shows the trajectory of the Roller 3 protrusion end over time. The bottom end of the roller protrusion has a circular trajectory with respect to the axis of rotation of the roller, and the center of the roller protrusion goes deepest when it reaches the center of the pot tray hole. Figure 17 shows the compression depth of the bed soil. The tip of the roller protrusion is lowered as deep as $7 \mathrm{~mm}$ from the top of the pot tray.
This is consistent with the target bed soil compressibility. Figure 18 shows the compressed shape of the bed soil by the conventional and design-improved rollers.

A roller was prepared with the improved design, and attached to the existing Roller 3 position to test the degree of bed soil compression (Figure 19). In the experiment, the pot-seeding machine was operated, and three arbitrary seeding holes in the pot tray passed through Roller 3 were selected to measure the compression. A strong adhesive was sprayed on the bed soil to harden it and was cut in the center plane. A white spray was 
applied to the compression surface of the bed soil to enable visual confirmation of the degree of compression. As a result of the experiment, the bed soil was compressed by $7 \mathrm{~mm}$, which was consistent with the dynamic simulation (Figure 20).

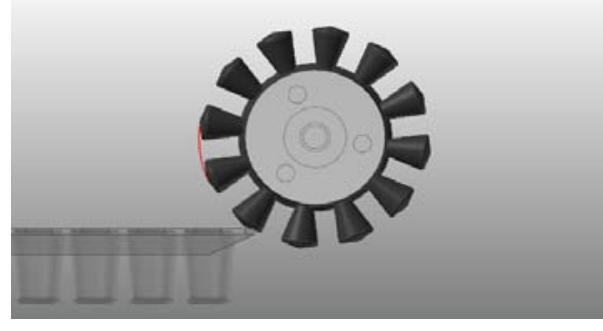

a.



c.

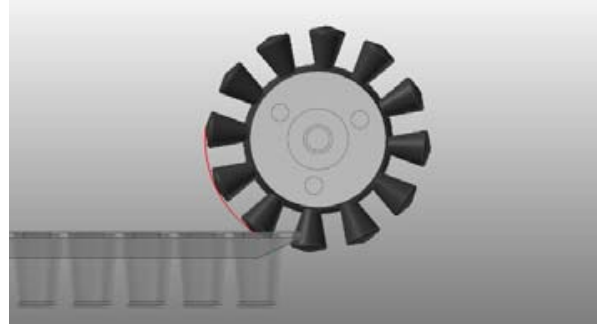

b.

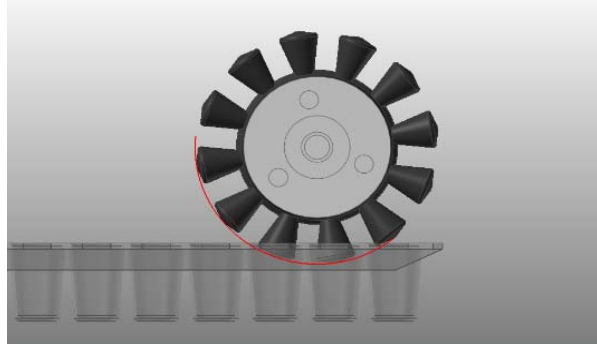

d.

Figure 16 Trajectory of roller end over time: $a \rightarrow b \rightarrow c \rightarrow d$

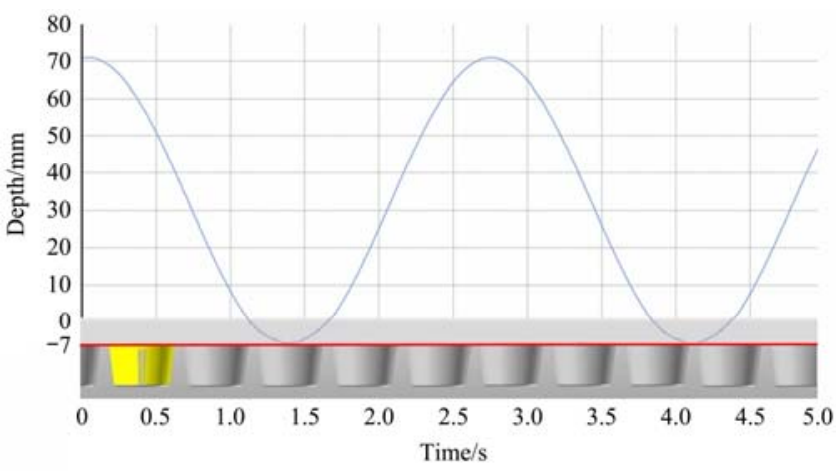

Figure 17 Compression depth of bed soil derived by dynamic analysis for optimized roller shape

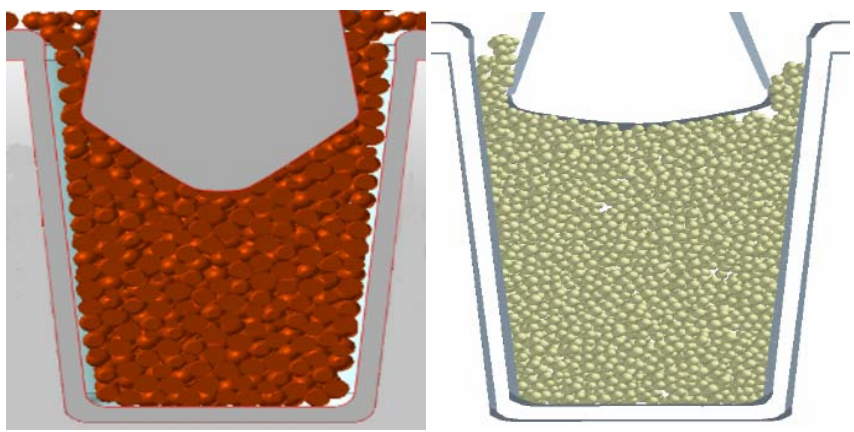

a. Before improved design

b. After improved design

Figure 18 Compaction shape of bed soil by Roller 3

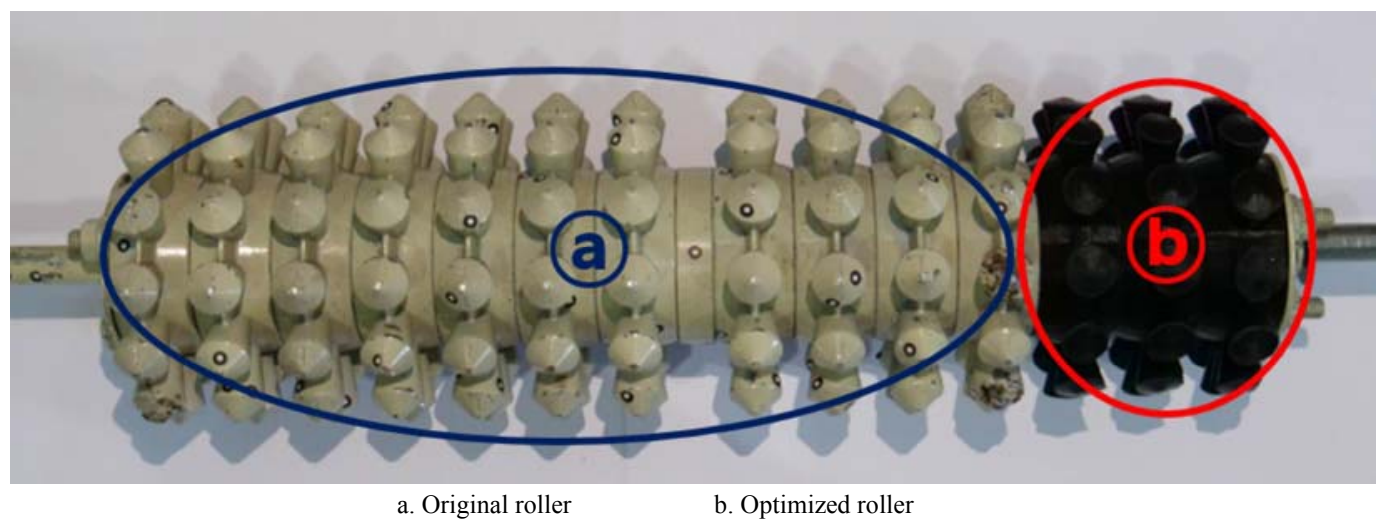

Figure 19 Adapting optimized roller shape to original roller
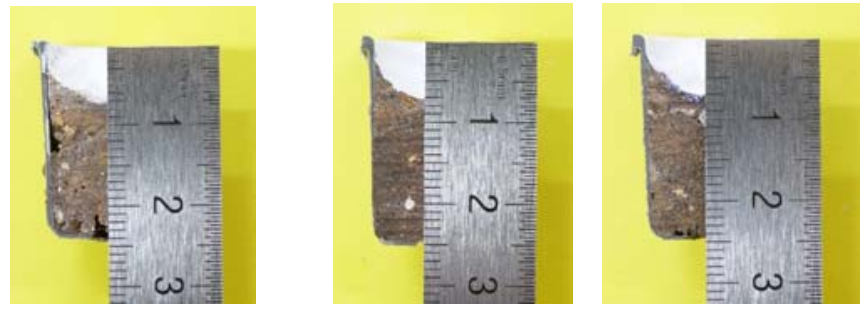

Figure 20 Compression depth of bed soil derived by the experiment for optimized roller shape (in three randomly selected spots)

\section{Conclusions}

The stress distribution and the maximum equivalent stress of the roller changed depending on the size of the design parameters. The maximum stress occurred mainly in the lower part of the roller protrusion or in the upper part of the bracket. When the safety factor decreased, the roller weight also decreased, while the safety factor increased, the roller weight increased. Applying the derived optimized parameters to the rollers could reduce the roller weight by $17.7 \%$ while the safety factor of 2.0 or higher is satisfied. Moreover, optimal bed soil compressibility was also obtained. 
In conclusion, if the improved design parameters in this study are applied to the existing roller-type pot-seeding machine, the production efficiency of healthy seedling could increase while the roller weight is minimized.

\section{Acknowledgements}

This work was supported by Korea Institute of Planning and Evaluation for Technology in Food, Agriculture, Forestry and Fisheries (IPET) through Agriculture, Food and Rural Affairs Research Center Support Program, funded by Ministry of Agriculture, Food and Rural Affairs (MAFRA) (716001-7). This research was also supported by Basic Science Research Program through the National Research Foundation of Korea (NRF) funded by the Ministry of Education (NRF-2017R1D1A3B03033338).

\section{[References]}

[1] FAOSTAT. Food and agriculture organization of the united nations: agriculture and consumer protection. Roma. 2014. http://www.fao.org/faostat/en/\#data/QC. Accessed on [2017-09-07]

[2] Ha D J, Yu C H, Chou C K, Jo S J, Li J S. Analysis between Chinese and Korean vegetable production system. J. Korean Soc. Int. Agric. 2015; 27(5): 614-621.

[3] RDA. Rural development administration: Survey on the vegetable seed market of India. National Institute of Horticultural and Herbal Science, 2012; pp.175-196.

[4] RDA. Rural development administration. automatic seeding production system. RDA Interrobang, 2016; 166: 3-13.

[5] Ha I J. Establishment of management system in plug onion seeding technology for mechanical transplanting. Thesis, Kyungpook National University, 2014; pp.69-77.

[6] Hwang S J, Kim D H, Nam J S. Design improvement research of onion port-seeding machine for increasing mechanization ratio. Conference of Korean Society for Agricultural Machinery, 2016; 21(2): 93.

[7] Jung S M. Mechanical engineering new edition. Seoul: Bookshill Press, 2009; 704p.

[8] Meriam J L, Kraige L G. Engineering mechanics dynamics. 6th ed. USA: John Wiley \& Sons Inc Press, 2008; 335p.

[9] Kim J I. Publish committee for mechanical terminology. Seoul: Iljinsa Press, 1990; pp.156-123.

[10] Juvinall R C, Marshek K M. Machine component design. 5th ed. USA: John Wiley \& Sons Inc Press, 2012; pp.841-47

[11] Ha I J. Development of high efficiency transplanting system for labor-saving of onion production. Ministry of Agriculture, Food and Rural Affairs, 2015; pp.158-160

[12] Jang S W, Lim M S. Robust design technology for plastic parts reliability. Seoul: Kijeon Research Center Press, 2006; pp.344-352.

[13] Yun T Y, Yoo P J, Kim Y B. Determination of DEM input parameters for dynamic behavior simulation of aggregates. Int. J. Highway Eng., 2014; 16(1): 21-30.

[14] Lee M J. Information cultivated plant skill: Seeding season and seeding skill of onion. Gyeongsangbuk-do Agricultural Research \& Extension Services: $\quad$ Daegu. 2011. http://db.gba.go.kr/sub02/ sub01_view.php?info_no=461\&kind_code=13. Accessed on [2017-09-07]

[15] RDA. Rural development administration. Information Cultivated Plant Skill: Production Skill of Onion Plug Seedling. Rural Development Administration: Jeonju. 2015. http://www.nongsaro.go.kr/ portal/ps/psb/psbk/kidoContentsFile View.ps? kidofcomdtyNo=13876. Accessed on [2017-07-13].

[16] Kim M S, Kang D O, Heo S J. Innovative design optimization strategy for the automotive industry. Int. J. Automot. Tech., 2014; 15(2): 291-301. 